\section{JUBILACIÓN DEL DR. D. CONSTANTINO HERRANZ FERNÁNDEZ}

El pasado mes de noviembre de 2002 cumplió 65 años y se jubiló (en perfecto estado de salud) el Jefe del Servicio de Oncología Médica del Hospital Universitario La Fe de Valencia, Dr. D. Constantino Herranz Fernández. Nacido en un pueblo de Cuenca, tras su licenciatura en Medicina (Valencia) permaneció varios años en Alemania donde completó su formación en Medicina Interna. A su regreso se incorporó como Jefe de la Sección de Oncología Médica del Hospital La Fe (1970-1980); posteriormente fue Jefe de Servicio de Oncología Médica en el Instituto Valenciano de Oncología (1981-1988) y nuevamente en el Hospital La Fe (1992-2002).

Miembro fundador de la SEOM, entre 1983 y 1985 fue Vicepresidente y desde 1985 a 1987 Presidente de su Junta Directiva. Organizó en Valencia (1986) el $1^{\text {er }}$ Congreso Nacional conjunto de las Sociedades Oncológicas Españolas (SECO, SEOM, AERO, ASEICA), que llevaría a la creación de la FESEO. Ha pertenecido a otras sociedades como ESMO, Asociación Española de Senología y Patología Mamaria, Sociedad Española del Dolor, Sociedad Española de Salud Pública y Administración Sanitaria y Sociedad Española de Médicos Rurales y Generalistas (Miembro de Honor). Ha formado parte de los Comités Científicos de las revistas Oncología y Revisiones en Cáncer.

Fue miembro de la Comisión Nacional de la especialidad de Oncología Médica (Ministerio de Sanidad y
Consumo) desde 1987 a 1992, así como Coordinador (1988-1990) y Director (1990-1995) del Plan Integral de Lucha contra el cáncer de la Comunidad Valenciana (Consellería de Sanitat i Consum). También fue miembro del Grupo de Trabajo de Salud Laboral de la Consellería de Sanitat. Asimismo ha pertenecido a las Comisiones Nacionales de la FESEO para la elaboración de los Libros Blancos de la Oncología en España (el primero publicado en 1988, el segundo en 1995 y el tercero en 2002).

Junto al desarrollo de la especialidad de Oncología Médica y la defensa del tratamiento multidisciplinario, probablemente su principal contribución a la Oncología haya sido la creación y desarrollo del Programa de Prevención del Cáncer de Mama de la Comunidad Valenciana (uno de los principales en $\mathrm{Eu}-$ ropa), del que es su Asesor Oncológico. Desde 1992 a 2000 se han estudiado 297.825 mujeres entre 45 y 65 años en las 21 unidades de diagnóstico precoz creadas, con unas tasas de detección de 0,32\%-0,47\%.

El Dr. Herranz se jubila en el Hospital Universitario La Fe como Coordinador Oncológico y Presidente de la Comisión Hospitalaria de Tumores, en un Servicio de Oncología Médica dotado hoy en día de un Jefe de Sección, ocho Médicos Adjuntos y ocho Médicos Residentes (dos por año de residencia). Todos nosotros deseamos que sea muy feliz en esta nueva trayectoria que ahora comienza.

J. APARICIO 